Revista Destaques Acadêmicos, Lajeado, v. 12, n. 4, 2020. ISSN 2176-3070

DOI: http://dx.doi.org/10.22410/issn.2176-3070.v12i4a2020.2401

http://www.univates.br/revistas

\title{
ANÁLISE MODAL NUMÉRICA DE UMA PASSARELA DE PEDESTRES
}

\author{
Guilherme Leite Lago', Gabriel Birck², Marcelo André Toso ${ }^{3}$
}

\begin{abstract}
Resumo: Passarelas são utilizadas para realizar a travessia de um local a outro devido a terrenos acidentados, rodovias ou lagoas e rios. Geralmente, são estruturas esbeltas, mas que devem ser bem dimensionadas, para manter a segurança e tranquilidade dos usuários. Entretanto, existem efeitos que podem surgir devido a interação entre o usuário e a estrutura que geram vibrações que podem ocasionar desconfortos aos pedestres e avarias, ou até mesmo o colapso da estrutura. Nesse contexto, o objetivo do trabalho foi realizar uma análise pelo método de elementos finitos da passarela que faz a ligação do prédio nove e onze da Universidade do Vale do Taquari (Univates), para obtenção das frequências naturais e dos modos de vibração da estrutura. Este estudo é motivado através de percepções de pedestres que verificaram que a estrutura possui movimentos vibratórios elevados. Preocupado com o conforto e principalmente com a segurança dos pedestres em geral, o trabalho apresenta comparações entre as frequências resultantes da estrutura e as frequências do caminhar de pessoas. Verifica-se que o telhado e arcos laterais apresentam vibrações susceptíveis aos pedestres, enquanto o piso da estrutura comporta-se de modo mais estável.
\end{abstract}

Palavras-chave: Passarelas. Análise Modal. Método de Elementos Finitos.

\section{INTRODUÇÃO}

Durante o último século, ocorreu um grande avanço tecnológico na engenharia. A disponibilidade de novos materiais, a maior resistência mecânica dos componentes, a redução de custos de fabricação e do peso de peças e estruturas. Um ser humano age como parte integral em muitos sistemas de engenharia, sendo um exemplo as estruturas de passarelas. Em contrapartida,

1 Mestrando em Engenharia Mecânica, Universidade Federal do Rio Grande do Sul. gui_llago@hotmail.com

2 Doutorando em Engenharia Mecânica, Universidade Federal do Rio Grande do Sul. gabriel.birck@gmail.com

3 Doutor em Engenharia Mecânica, Professor do Instituto Federal de Santa Catarina. 
a transmissão de vibração a seres humanos resulta em desconforto e perda de eficiência (RAO, 2009). Alguns problemas dinâmicos podem ocorrer em estruturas devido à coincidência ou proximidade das frequências de excitação e frequências naturais do sistema, gerando ressonância. Esse fenômeno pode causar problemas estruturais ou até mesmo o colapso da estrutura.

Este trabalho analisa uma passarela metálica com pilares de concreto localizada na Universidade do Vale do Taquari (Univates). Essa passarela cruza um corpo d'água fazendo a ligação entre dois prédios dessa universidade. Com o grande fluxo de pessoas que cruzam a estrutura, a oscilação da mesma é perceptível, ocasionando um desconforto para os pedestres. O objetivo deste trabalho é realizar uma análise modal numérica desta passarela, visando obter suas frequências naturais e modos de vibração estrutural para posterior comparação com as frequências geradas por pedestres.

\section{FUNDAMENTAÇÃO TEÓRICA}

Stoyanoff e Hunter (2003) relatam que as vibrações geradas por pedestres não são suscetíveis às estruturas com vãos curtos. Quanto maior for a distância entre os vãos, menores serão as frequências naturais da estrutura. Quando as interações humanas sobre a estrutura são relevantes, é fundamental observar para que não ocorra o fenômeno de ressonância, isto é, que a frequência das forças produzidas por pedestres não esteja em sincronia com as frequências naturais da estrutura, evitando que as vibrações sejam amplificadas.

Segundo, Stoyanoff e Hunter (2003), durante o caminhar, os seres humanos apresentam esforços verticais cujas frequências variam entre $1,5 \mathrm{~Hz}$ a 4,0 Hz; enquanto que as forças laterais possuem frequências entre $0,75 \mathrm{~Hz}$ a $2,0 \mathrm{~Hz}$. Os autores afirmam que um estudo mais detalhado das vibrações em passarelas deve ser realizado caso houver frequências naturais inferiores a 5,0 $\mathrm{Hz}$ na direção vertical e $2,5 \mathrm{~Hz}$ na direção lateral.

Zivanovic et al. (2005a) relatam que existem interações entre estruturas e pedestres, pois as frequências naturais observadas em estruturas de aço, concreto, madeira, materiais compósitos, entre outros, podem diversas vezes coincidir com algumas frequências provocadas por forças humanas. Uma pessoa produz forças dinâmicas em três direções: vertical, horizontal-lateral e horizontal-longitudinal durante a caminhada. Essas forças são geradas através da aceleração e desaceleração da massa do corpo. De acordo com Zivanovic et al. (2005b), a maioria dos critérios de projetos avaliam os níveis de vibrações estruturais considerando a força de excitação como uma força senoidal com velocidade constante. Os autores destacam que a frequência da caminhada vertical varia de 1,5 a 2,4 Hz, ou em múltiplos inteiros do valor, caso harmônicos subsequentes sejam considerados. Normalmente, os três primeiros harmônicos da caminhada são avaliados e se verifica a coincidência dessas frequências com as frequências naturais estruturais. Em outra publicação, Zivanovic et al. (2009) 
afirmam que, o ser humano é o receptor das vibrações estruturais, sendo assim, o mesmo tem a tendência de alterar seu padrão de caminhada ao perceber que há vibrações na estrutura. Os autores observaram que as pessoas alteram a taxa de passos, reduzindo a magnitude da força vertical quando percebem vibrações na estrutura.

Vibrações estruturais não necessariamente causam o colapso da estrutura, mas podem gerar desconforto aos pedestres. Um dos casos clássicos é a Millenium Bridge (Figura 1a), inaugurada em 2000 e localizada na cidade de Londres, que apresentou vibrações excessivas durante a cerimônia de abertura e após dois dias foi interditada, ficando fechada durante dois anos para eliminar as excessivas vibrações laterais quando o número de pessoas chegava a dois mil. A passarela foi reaberta ao público em 2002. Outro exemplo é a passarela Simone de Beauvoir (Figura 1b) sobre o rio Sena na França, ensaios dinâmicos e estáticos foram realizados após a inauguração da passarela com a finalidade de avaliar as vibrações estruturais, pois em algumas situações os pedestres relataram uma sensação de desconforto ao cruzar a estrutura.

Figura 1 - Passarelas que indicaram problemas devido à vibração a) Millenium Bridge, Londres; b) Simone de Beauvoir, Paris.

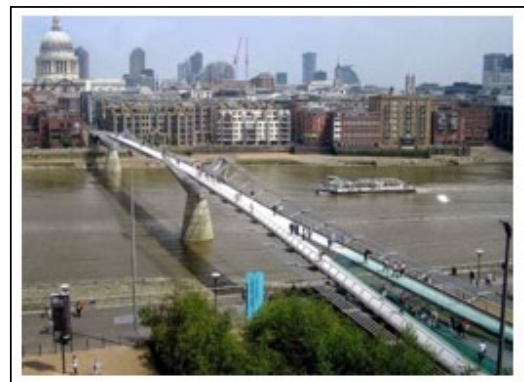

(a)

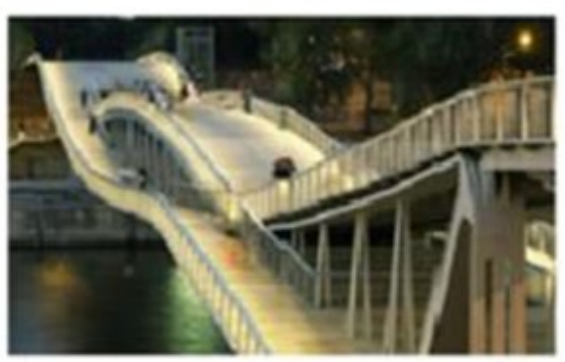

(b)

Fonte: https://www.google.com/search?q=passarelas+pedestres626

\subsection{Análise modal}

Uma análise modal pode ser teórica ou experimental, através desta, podem ser determinadas as características dinâmicas de uma estrutura, a fim de determinar as frequências naturais e modos de vibração estrutural. Para este estudo, o Princípio da Conservação da Energia é importante. O sistema é conservativo se nenhuma força externa atuar, por exemplo, atrito e membros não elásticos (exceto ação gravitacional e outras forças potenciais), com isso, a energia total do sistema se mantém constante (RAO, 2009). O Princípio da Conservação da Energia pode ser expresso pela Eq. (1): 


$$
T+\Pi=\text { constante, }
$$
Eq. (2):

Onde T é a energia cinética e $\Pi$ a energia potencial, ou ainda usando a

$$
\frac{d}{d t}(T+\Pi)=0
$$

A energia cinética (T) é obtida através da Eq. (3), onde m é a massa e o $\dot{x}$ é a velocidade.

$$
T=\frac{1}{2} m \dot{x}^{2},
$$

A energia potencial ( $\Pi)$ é obtida através da Eq. (4).

$$
\Pi=\frac{1}{2} k x^{2} \text {, }
$$

Onde $k$ é a rigidez do sistema e o $x$ é o deslocamento. $\mathrm{O}$ resultado da substituição das Eq. (3) e (4) nas Eq. (1) ou (2), é a Eq. (5) do Princípio da Conservação da Energia.

$$
m \ddot{x}+k x=0,
$$

Onde $\ddot{x}$ é a aceleração estrutural. A equação anterior pode ser reescrita para um sistema de $\mathrm{n}$ graus de liberdade e assim a análise modal em vibrações livres, sem amortecimento, é dada pela Eq. (6):

$$
M \ddot{u}+K u=0 \text {, }
$$

Onde $\mathrm{M}$ e K são as respectivamente matrizes de massa e rigidez, e ü e u são vetores de aceleração e deslocamento, respectivamente, conforme Eq. (7) e (8):

$$
\begin{aligned}
& u=\phi \operatorname{sen}(\omega t), \\
& \ddot{u}=-\omega^{2} \phi \operatorname{sen}(\omega t),
\end{aligned}
$$

Onde, $\phi$ é a amplitude modal, $\omega$ são as frequências naturais e $t$ é o tempo. Substituindo as Eq. (7) e (8) na Equação 6 e fazendo simplificações algébricas, chega-se na Eq. (9):

$$
\left(K-\omega^{2} M\right)\{\phi\}=0
$$

Pela Eq. (9), duas soluções são possíveis do problema de autovalores, a primeira é a solução trivial dada por $\phi=0$, e a segunda solução é obtida quando o primeiro termo é igual à zero, isto é:

$$
\operatorname{det}\left[\left(K-\omega^{2} M\right)\right]=0
$$

Para obter a forma mais usual do problema de autovalores, faz-se $\lambda=\omega^{2}$, conforme Eq. (11): 


$$
\operatorname{det}[(K-\lambda M)]=0 \text {, }
$$

Onde $\lambda$ são as $n$ frequências naturais ao quadrado do sistema.

\subsection{Elementos finitos}

Para resolver problemas complexos, o Método de Elementos Finitos (MEF) é uma excelente alternativa para solucionar problemas estáticos e dinâmicos. $\mathrm{O}$ estudo por análise numérica é realizado geralmente utilizando o MEF, começando por uma análise teórica na qual as propriedades físicas e geométricas da estrutura são caracterizadas. Antes de definir as condições de contorno, é necessário realizar uma inspeção detalhada para observar os tipos de apoio, fixações, dimensões em geral e materiais utilizados. Para a formulação de elementos finitos em dinâmica, o Princípio de Hamilton é necessário. Esse princípio é também conhecido como princípio do menor esforço, pois dentre todas as trajetórias possíveis que um sistema pode se mover de um ponto a outro em um intervalo de tempo, a trajetória seguida será aquela que minimiza a integral de tempo da diferença entre as energias cinética $(T)$ e potencial $(\Pi)$ do sistema (REDDY, 2005). O princípio é escrito de acordo com a Eq. (12):

$$
\int_{t_{1}}^{t_{2}} \delta(T-\Pi) d t=0
$$

Onde $\delta$ é símbolo para representar a variação e t1 e t2 são os instantes nos quais a configuração do sistema é conhecida. Considerando material elástico linear e sem carregamento externo (vibração livre), a energia potencial total do sistema $\Pi$ e a energia cinética $T$, primeiramente, são determinadas a partir das Eq. (13) e (14):

$$
\begin{aligned}
& \Pi=\frac{1}{2} \int_{V}\{\sigma\}^{T}\{\varepsilon\} d V, \\
& T=\frac{1}{2} \int_{V} v^{2} d m=\frac{1}{2} \int_{V} \rho v^{2} d V,
\end{aligned}
$$

Onde $v$ é a velocidade de cada um dos graus de liberdade, a massa específica do material é indicado por $\rho$; $\varepsilon$ é o tensor de deformações e $\sigma$ é o tensor de tensões; $V$ o volume de um elemento finito. Tensões e deformações podem ser escritas em notação matricial, Eq. (15) e (16) respectivamente.

$$
\begin{aligned}
& \{\sigma\}=[C]\{\varepsilon\} \\
& \{\varepsilon\}=[D]\{u\}
\end{aligned}
$$

Onde $C$ é a matriz constitutiva e $D$ é a matriz de operadores diferenciais.

O campo de deslocamentos $u$ é descrito através de funções de interpolações $\left(N_{i}\right)$, conforme Eq. (17):

$$
\{u\}=\sum_{i=1}^{n} N_{i}(x) q_{i}(t)
$$


Para um elemento de $n$ nós, os deslocamentos, as velocidades, as acelerações e o tensor de deformação são dados pelas Eq. (18), (19), (20) e (19):

$$
\begin{aligned}
& u(x, t)=[N]\{q\} \\
& \dot{u}(x, t)=[N]\{\dot{q}\} \\
& \ddot{u}(x, t)=[N]\{\ddot{q}\} \\
& \{\varepsilon\}=[B]\{u\}
\end{aligned}
$$

As energias cinética e potencial são dadas pelas Eq. (22) e (23). Com isso, o Princípio de Hamilton pode ser aplicado, resultando na Eq. (24).

$$
\begin{aligned}
& \Pi=\frac{1}{2} \int_{V}\{q\}^{T}[B]^{T}[C]\{B\}\{q\} d V \\
& T=\frac{1}{2} \int_{V} \rho\{N\}^{T}[N]\{\dot{q}\} d V \\
& \int_{V}[B]^{T}[C]\{B\} d V\{q\}+\int_{V} \rho[N]^{T}[N] d V\{\ddot{q}\}=0
\end{aligned}
$$

Onde $\{q\}$ é o vetor de deslocamentos nodais e $\{\ddot{q}\}$ o vetor de acelerações nodais, conforme Eq. (25):

$$
\{q\}=\left\{\begin{array}{c}
q_{1} \\
q_{2} \\
\vdots \\
q_{n}
\end{array}\right\} ;\{\ddot{q}\}=\left\{\begin{array}{c}
\ddot{q}_{1} \\
\ddot{q}_{2} \\
\vdots \\
\ddot{q}_{n}
\end{array}\right\}
$$

Sendo assim, a Eq. (24) pode ser reescrita conforme Eq. (26):

$$
[K]\{q\}+[M]\{\ddot{q}\}=0
$$

Considerando as Eq. (27) e (28):

$$
\begin{aligned}
& {[K]=\int_{V}[B]^{T}[C][B] d V} \\
& {[M]=\int_{V} \rho[N]^{T}[N] d V}
\end{aligned}
$$

Assumindo que as respostas do sistema são harmônicas (RAO, 2009), o deslocamento nodal pode ser escrito em função do deslocamento global $(u)$ do sistema, dado pela Eq. (29).

$$
\{q\}=\{u\} e^{-i \omega t}
$$

Após as substituições, chega-se na Eq. (30):

$$
[K]\{u\}+\omega^{2}[M]\{u\}=0
$$

Onde se avalia a matriz de rigidez $[K]$ e massa $[M]$, sendo $V$ o volume de um elemento finito. A sobreposição dessas matrizes elementares leva às matrizes de rigidez e massa globais. 


\section{PROCEDIMENTO METODOLÓGICOS}

Neste capítulo, informações técnicas da passarela e modelo CAD (computer aided design) estrutural são apresentados. Com essas informações, a análise numérica pelo MEF, através do software comercial ANSYS, 2016, é realizada para obter as frequências naturais e os modos de vibração da estrutura.

\subsection{Características gerais da passarela}

A estrutura da passarela é construída de aço SAE 1020. As colunas verticais para apoiar a estrutura são de concreto e estão espaçadas entre os vãos da passarela. As dimensões estruturais são: altura 2,5 metros, largura útil de 3,0 metros e comprimento total de 30,0 metros. A massa total da estrutura metálica é de $17.362 \mathrm{~kg}$. A Figura 2 apresenta a passarela em estudo.

Figura 2 - Estrutura da passarela metálica localizada na Univates.

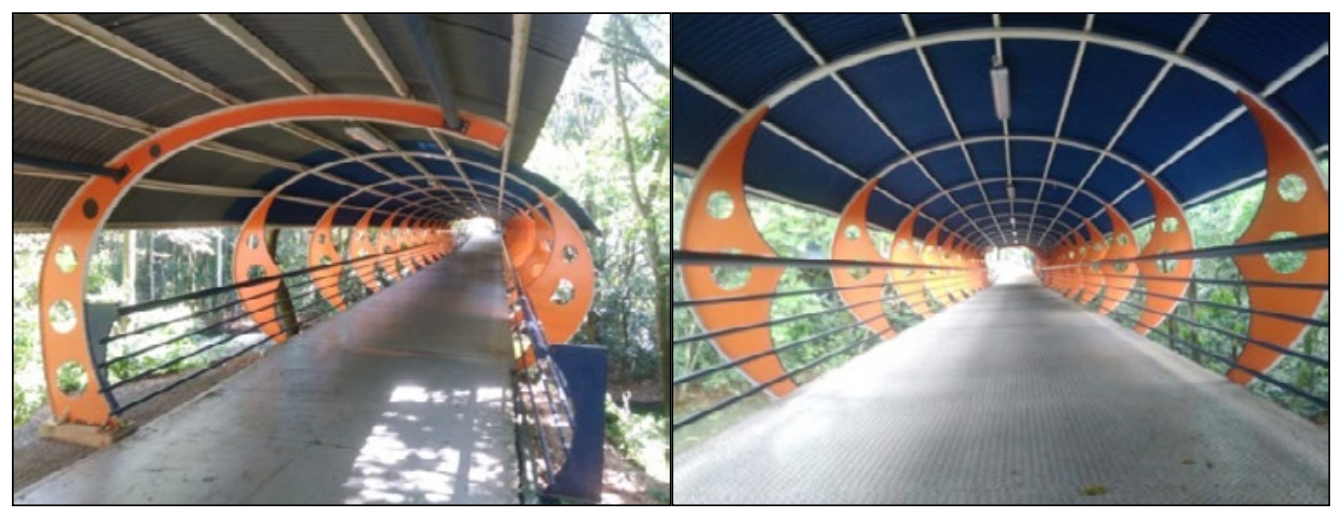

Fonte: $\mathrm{O}$ autor.

\subsection{Modelo CAD da Passarela}

O modelo em CAD é realizado no software Solid Edge versão ST6, conforme Figura 3. Com o modelo em CAD, a análise modal pelo MEF pode ser realizada utilizando o software comercial ANSYS. 
Figura 3 - Desenho 3D da passarela localizada na Univates.

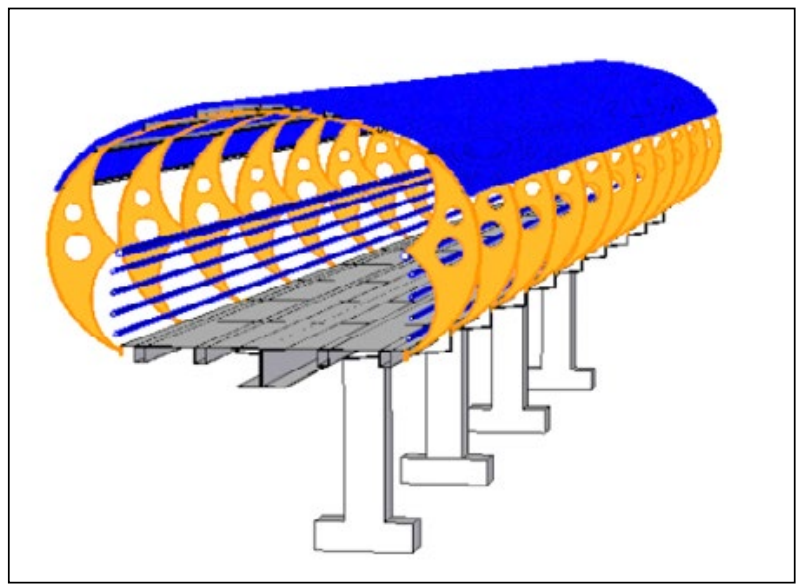

Fonte: $\mathrm{O}$ autor.

\subsection{Simulação numérica}

As propriedades do material utilizadas na simulação numérica são: módulo de elasticidade $210 \mathrm{GPa}$, coeficiente de Poisson de 0,29 e densidade igual a $7870 \mathrm{~kg} / \mathrm{m}^{3}$ (SHIGLEY, 2005). A Figura 4 apresenta as condições de contorno da simulação numérica, onde, na posição dos pilares é aplicado o tipo de engaste (deslocamentos e giros restritos) e no início e fim da passarela são aplicados apoios (deslocamento vertical restrito).

Figura 4 - Representação das condições de contorno.

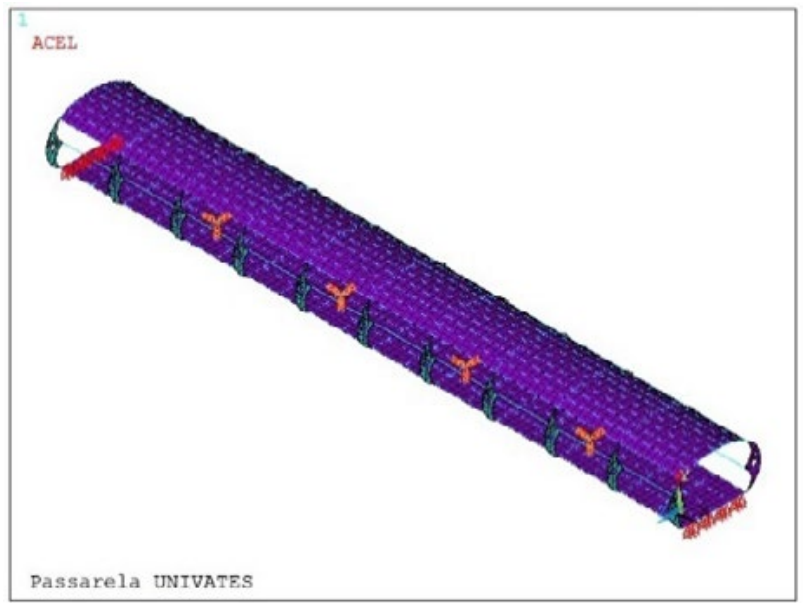

Fonte: $\mathrm{O}$ autor. 
As vigas do piso, o corrimão e as terças do telhado são modeladas com o elemento de viga BEAM189. O elemento é baseado na teoria de Timoshenko para vigas, que inclui os efeitos do cisalhamento. Trata-se de um elemento de viga quadrático de três nós com seis graus de liberdade por nó, isto é, permite o deslocamento e as rotações nas três direções ( $x, y$ e $z$ ) (ANSYS, 2016). Para a modelagem do telhado, da base (placas por onde os pedestres caminham) e dos "arcos" laterais utiliza-se o elemento de casca SHELL281. O SHELL281 é um elemento de casca de alta ordem de 8 nós, com seis graus de liberdade por nó, isto é, os deslocamentos e as rotações nas três direções cartesianas $(x, y$ e $z)$. Esse elemento é recomendado para a análise de cascas finas a moderadamente espessas e ele é governado pela teoria de cisalhamento de primeira ordem, ou também como conhecida, teoria de Mindlin-Reissner. Análises não lineares, grandes deslocamentos e/ou rotações e malhas irregulares são suportadas com este elemento (ANSYS, 2016).

\section{RESULTADOS E DISCUSSÃO}

Um estudo de convergência de malha é realizado para analisar a influência que os diferentes números de elementos geram no resultado final da simulação, conforme Figura 5.

Figura 5 - Convergência de Malha.

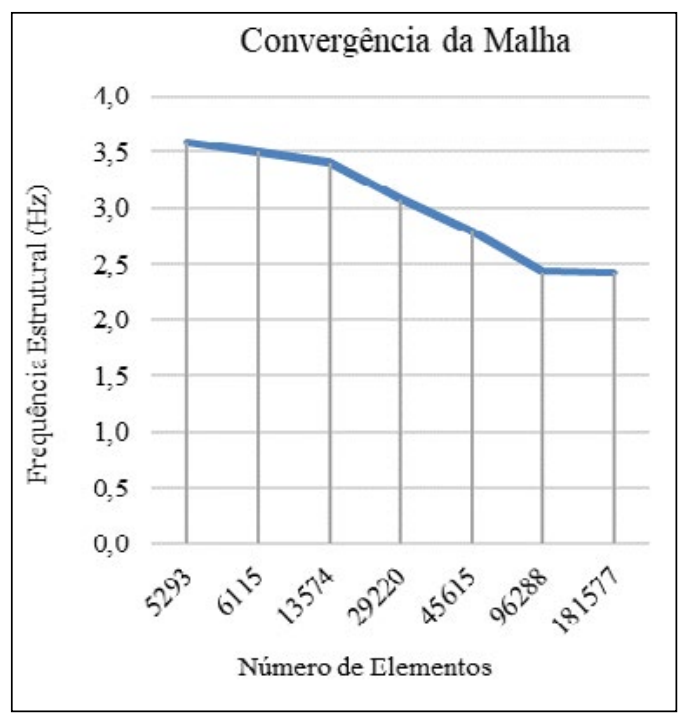

Fonte: $\mathrm{O}$ autor.

De acordo com o estudo de convergência de malha, foi utilizada no estudo uma malha com 96288 elementos. As quinze primeiras frequências naturais da estrutura obtidas pela análise modal são apresentadas na Tabela 1. 
Tabela 1 - Modos de vibração e frequências naturais da estrutura.

\begin{tabular}{c|c|c|c}
\hline Modo & Frequência $(\mathrm{Hz})$ & Modo & Frequência $(\mathrm{Hz})$ \\
\hline $1^{\circ}$ & 0,1508 & $9^{\circ}$ & 2,1519 \\
\hline $2^{\circ}$ & 0,1885 & $10^{\circ}$ & 2,3386 \\
\hline $3^{\circ}$ & 0,3550 & $11^{\circ}$ & 2,4350 \\
\hline $4^{\circ}$ & 0,7022 & $12^{\circ}$ & 2,9069 \\
\hline $5^{\circ}$ & 0,7552 & $13^{\circ}$ & 2,9373 \\
\hline $6^{\circ}$ & 1,9350 & $14^{\circ}$ & 4,5478 \\
\hline $7^{\circ}$ & 2,1244 & $15^{\circ}$ & 4,6771 \\
\hline $8^{\circ}$ & 2,1257 & & \\
\hline
\end{tabular}

Os cinco primeiros modos de vibração para cada frequência natural, isto é, a forma como a estrutura vibra em cada frequência, são apresentados nas Figuras 6.

Figura 6 - Modos de vibração estrutural: $1^{\circ}, 2^{\circ}, 3^{\circ}, 4^{\circ}$ e $5^{\circ}$ modo.

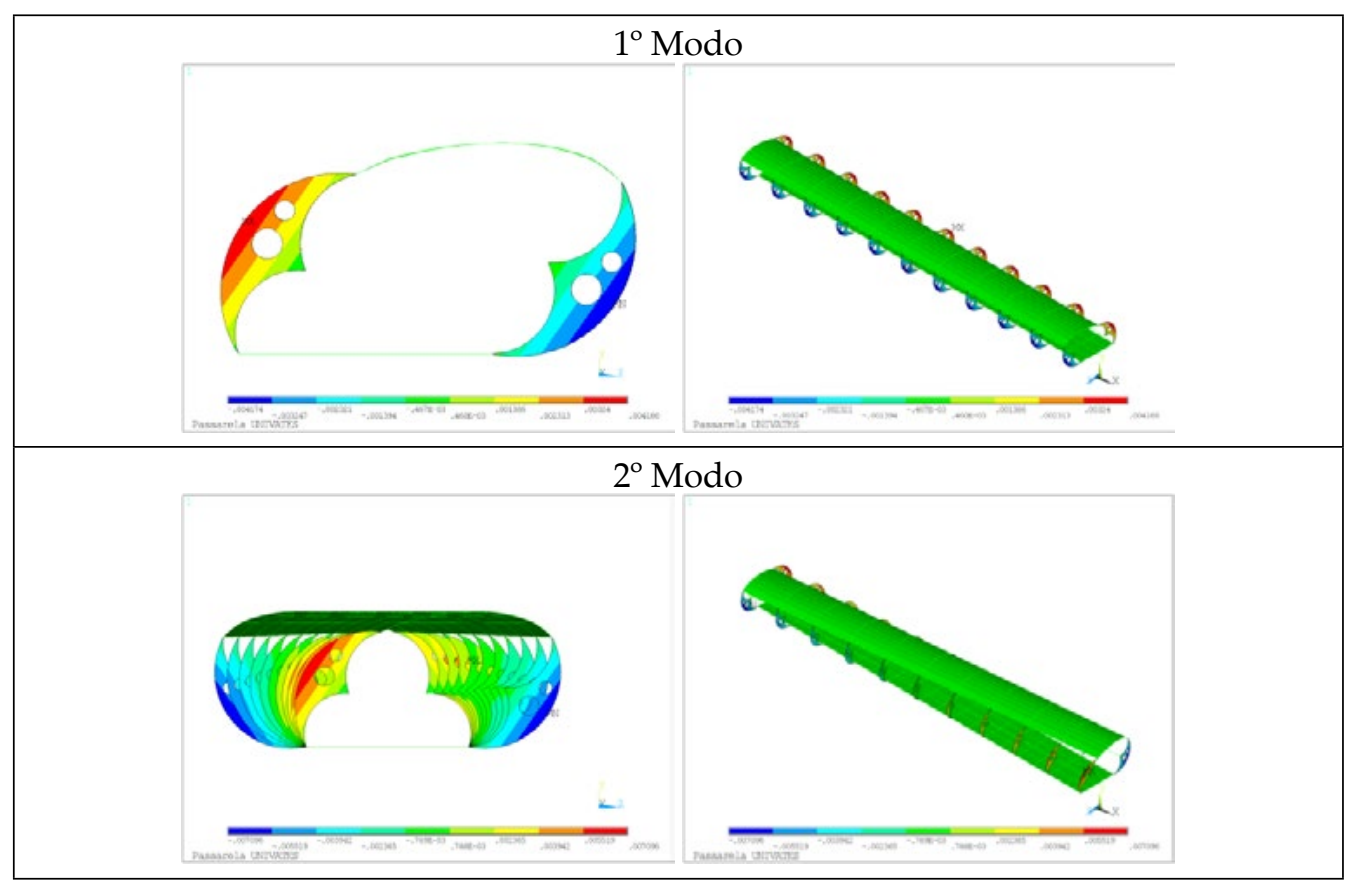




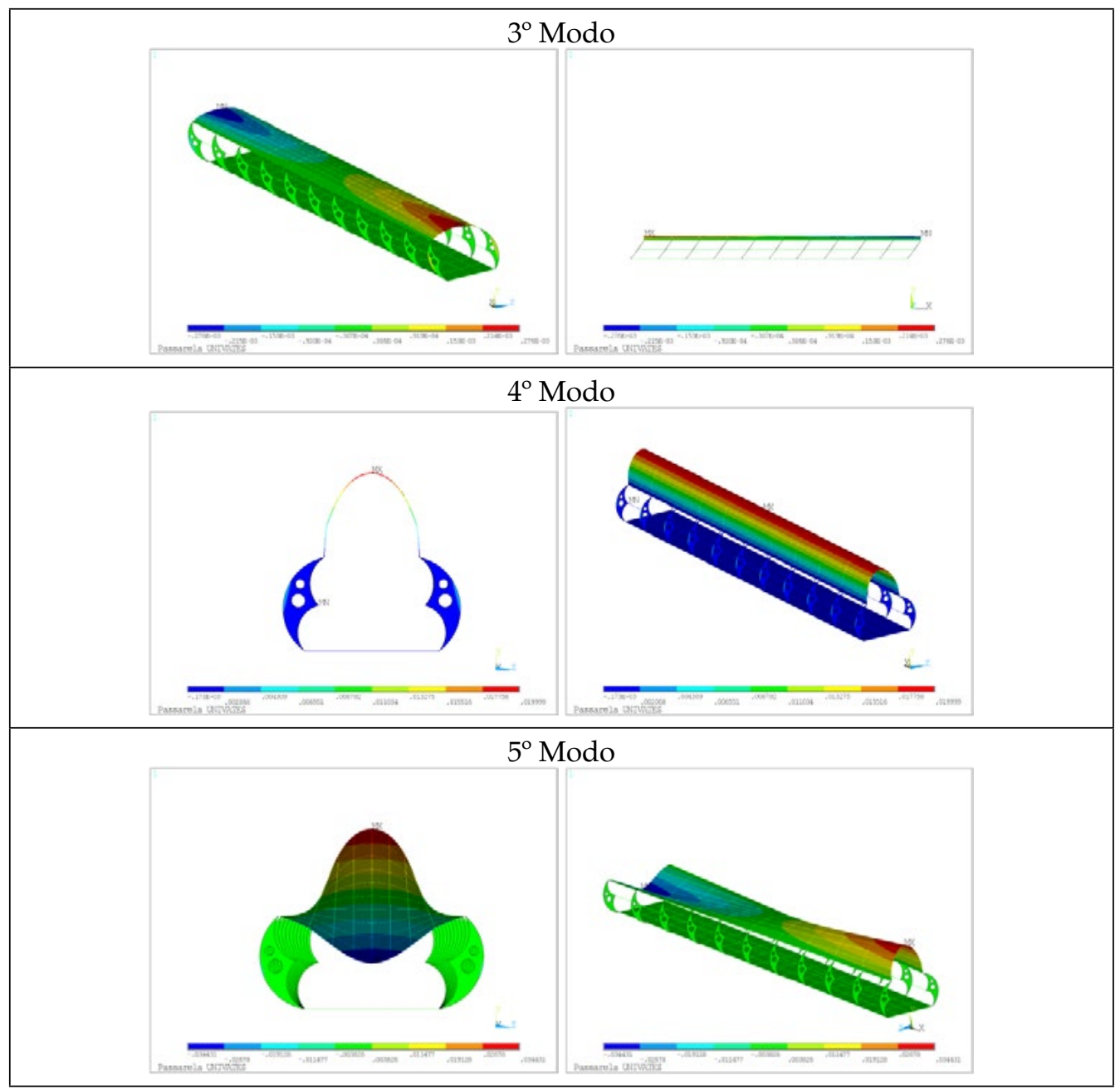

Fonte: $\mathrm{O}$ autor.

O primeiro modo de vibração, associado à frequência de $0,15 \mathrm{~Hz}$, é caracterizado pela flexão lateral dos arcos laterais e do telhado da passarela. Já o segundo modo de vibração é dado pela torção em relação ao eixo vertical de todos os arcos. O terceiro modo é caracterizado pela flexão longitudinal, deslocamentos longitudinais em fase, do conjunto arcos-telhado. As formas modais de vibração da quarta e da quinta frequência natural estão associadas à vibração local do telhado. $\mathrm{O}$ quarto modo apresenta uma flexão em relação ao eixo longitudinal (eixo $x$ ), isto é, deslocamentos verticais (eixo $y$ ) em fase de todo o telhado. Enquanto, o quinto modo é dado pela flexão em relação ao eixo lateral (eixo $z$ ), apresentando deslocamentos verticais opostos no início e fim da passarela. A Figura 7 apresenta os cinco modos de vibração estrutural subsequentes. 
Figura 7 - Modos de vibração estrutural: $6^{\circ}, 7^{\circ}, 8^{\circ}, 9^{\circ}$ e $10^{\circ}$ modo.

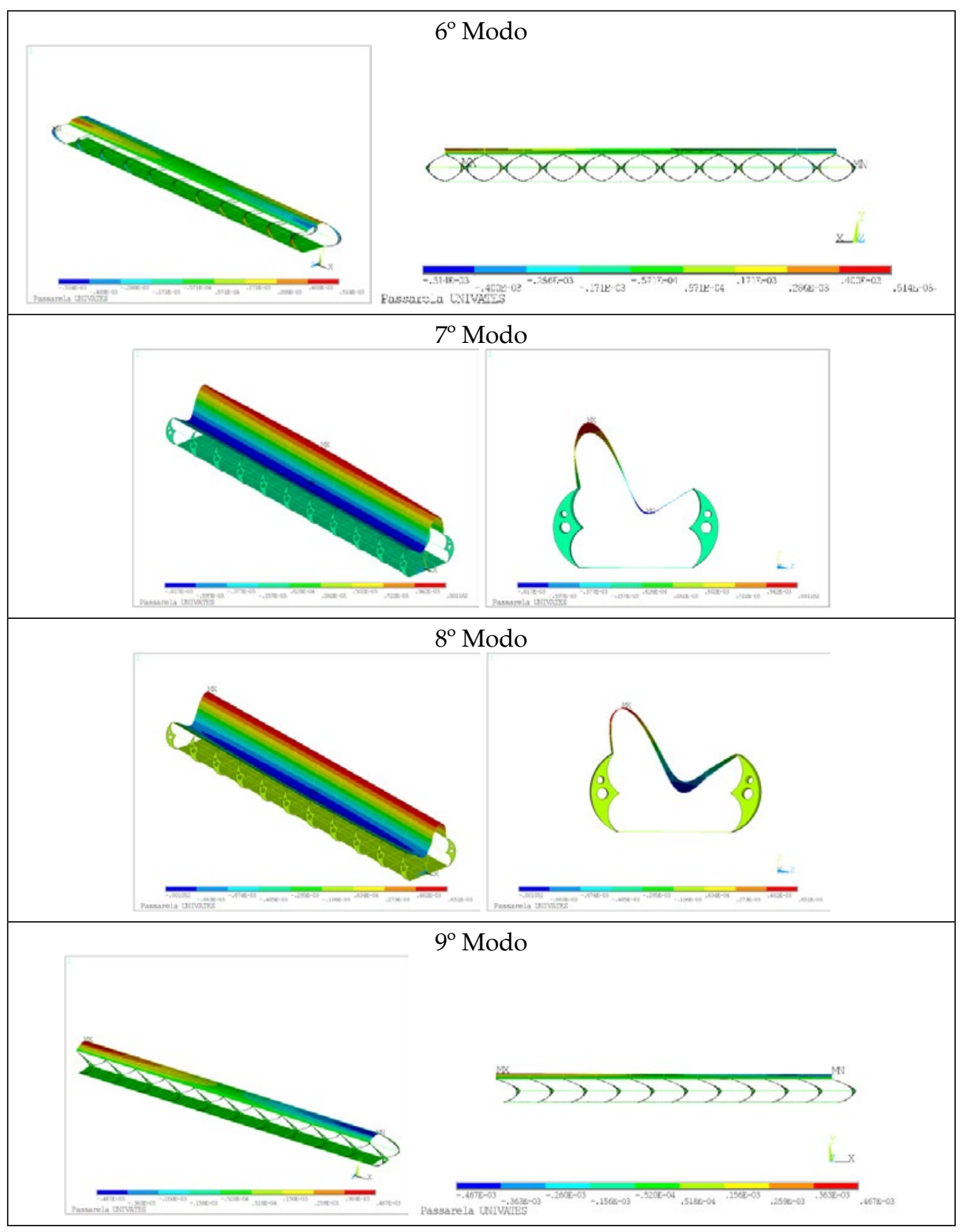




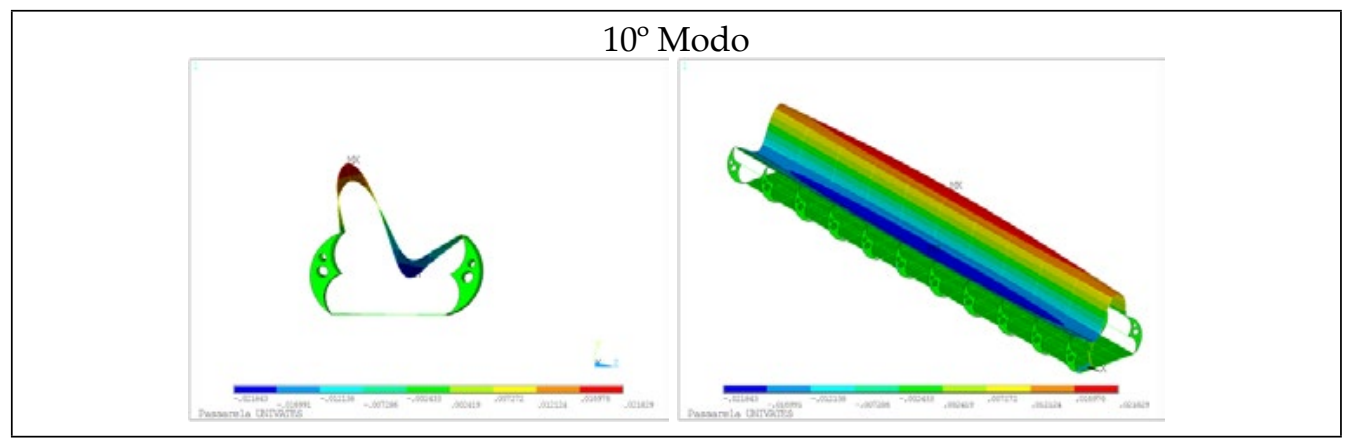

Fonte: $\mathrm{O}$ autor.

O sexto modo de vibração é caracterizado pela flexo-torção do conjunto arcos-telhado, onde há deslocamentos longitudinais dos arcos de forma opostas e a rotação do telhado devido à defasagem de deslocamentos entre os arcos da direita e da esquerda. Já o sétimo e oitavo modo de vibração são caracterizados pela flexão do telhado em relação ao eixo longitudinal. $\mathrm{O}$ nono modo de vibração é caracterizado pela flexão dos arcos, ocasionando deslocamentos longitudinais opostos entre a parte central dos arcos e o telhado. Já o décimo modo de vibração é caracterizado pela flexão do telhado em relação ao eixo longitudinal. A Figura 8 apresenta os demais modos de vibração estrutural.

Figura 8 - Modos de vibração estrutural: $11^{\circ}, 12^{\circ}, 13^{\circ}, 14^{\circ}$ e $15^{\circ}$ modo.

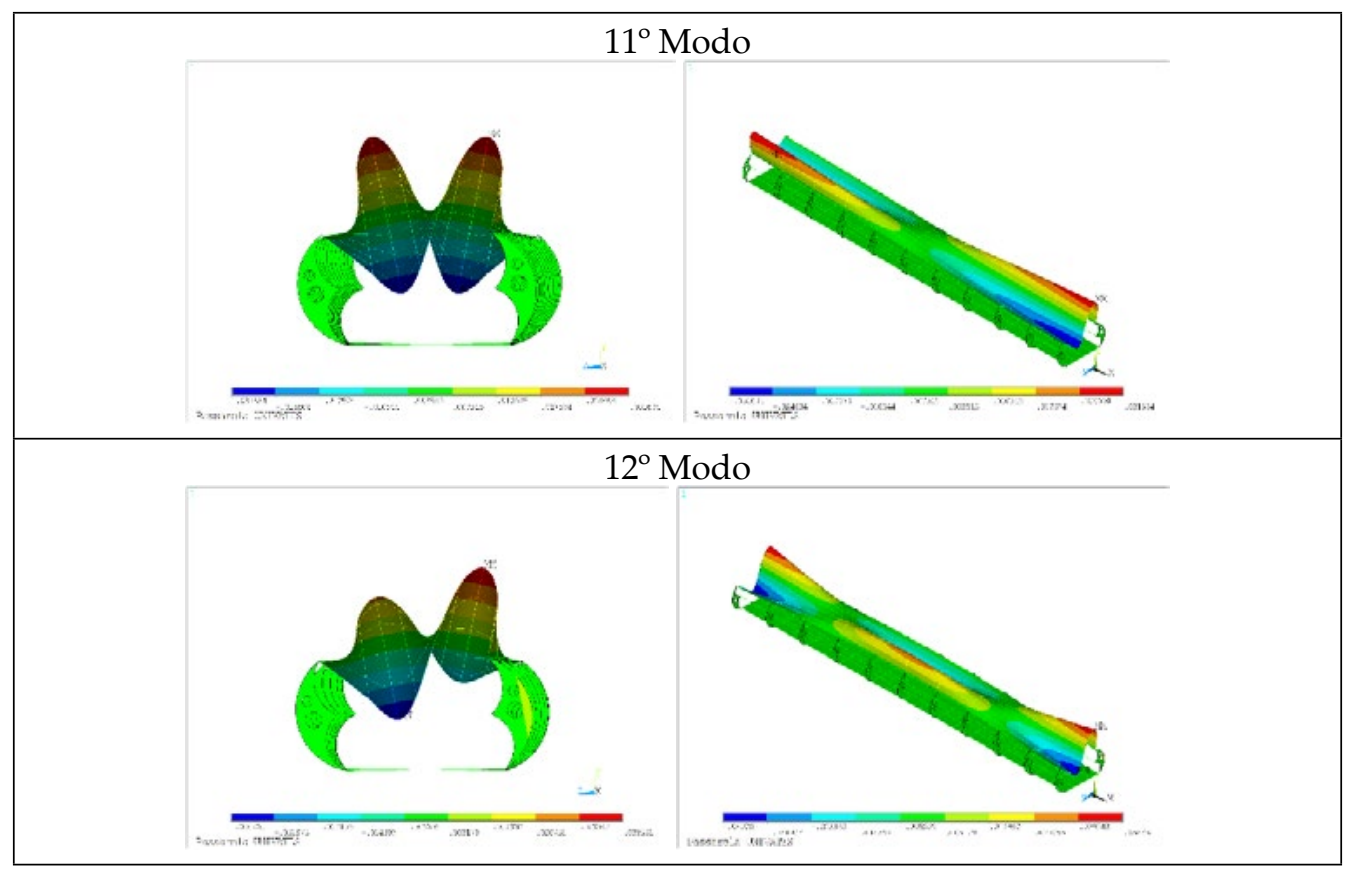




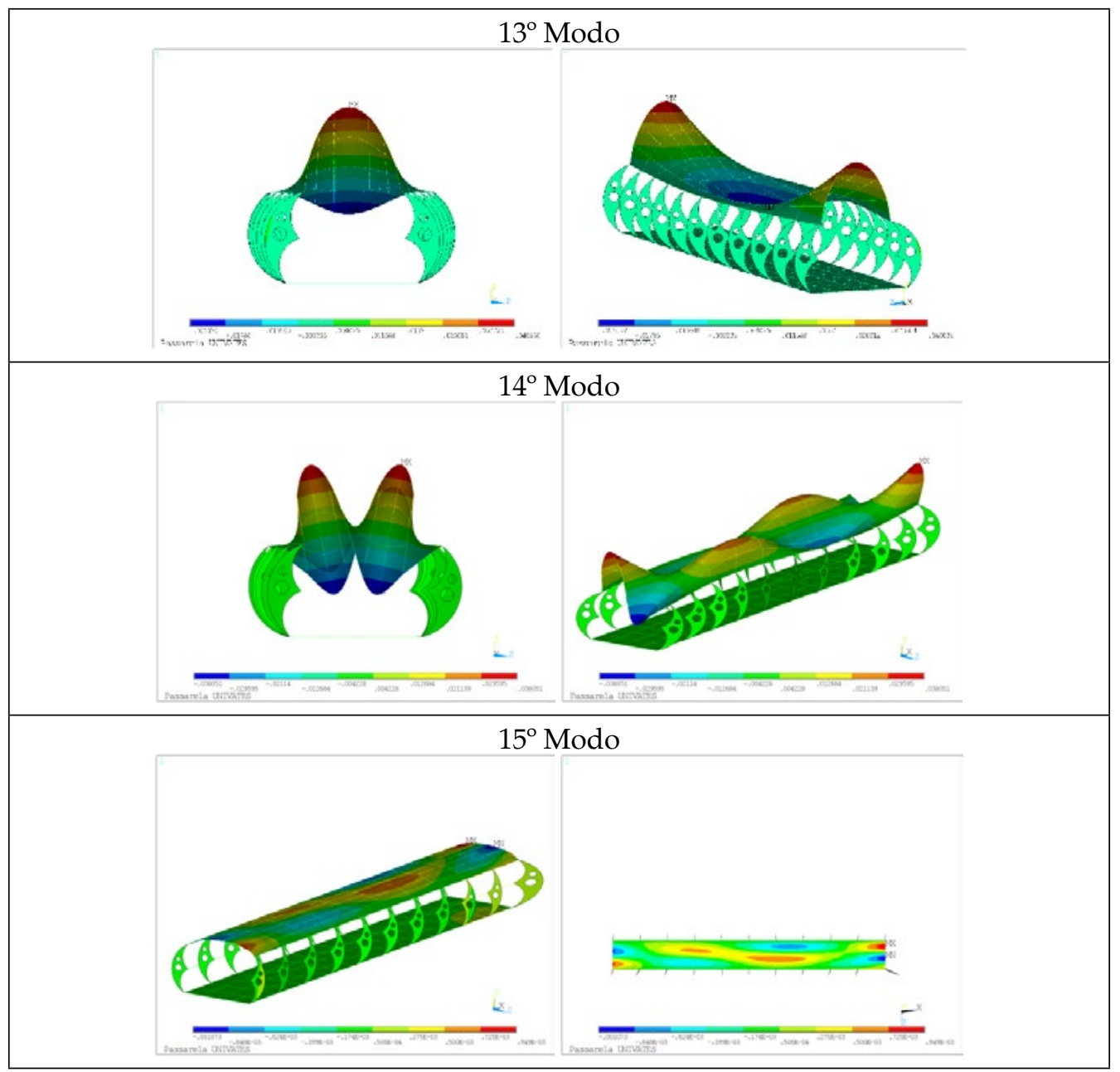

Fonte: $\mathrm{O}$ autor.

Da $11^{\mathrm{a}}$ à $14^{\mathrm{a}}$ frequência natural, os modos de vibração estão associados à vibração local do telhado, apresentando diversos modos de flexão do mesmo. Por fim, o $15^{\circ}$ modo de vibração, esta associado a uma vibração local de torção dos arcos.

Verificou-se que a estrutura apresenta frequências baixas conforme indicado na Tabela 1. Conforme apresentado nas figuras anteriores, a maioria das frequências naturais estruturais estão relacionadas à vibração da cobertura da passarela. Segundo os resultados dos modos de vibração, nota-se que o piso da estrutura é mais rígido que a cobertura e os "arcos" laterais da mesma.

Considerando os resultados das frequências naturais estruturais e as frequências do caminhar humano previamente citado por Stoyanoff e Hunter (2003), observa-se que podem haver coincidências entres essas frequências, gerando vibrações perceptíveis e incomodo aos pedestres. Observa-se que nas 
frequências do sexto e do nono modo, por exemplo, a forma de vibração não está atrelada exclusivamente a cobertura, mas também ao "arco" lateral. Desta forma, estas frequências são mais facilmente perceptíveis aos pedestres.

\section{CONCLUSÃO}

Os efeitos das vibrações de estruturas em pessoas têm ganhado cada vez mais importância no cenário mundial, sendo que essas vibrações podem ser analisadas de várias formas, considerando aspectos patológicos, fisiológicos e psicológicos, por exemplo, gerando desde pequenos desconfortos até sérios riscos à saúde. $\mathrm{O}$ corpo humano possui uma vibração natural. Se uma frequência externa coincide com a frequência natural do sistema, pode ocorrer o fenômeno de ressonância, gerando uma amplificação do movimento. A energia vibratória é absorvida pelo corpo, como consequência da atenuação promovida pelos tecidos e órgãos. Destaca-se que a Norma ISO 2631 define métodos de avaliação da exposição humana às vibrações de corpo inteiro, onde as pessoas são sensíveis a vibrações da ordem de 1 a $80 \mathrm{~Hz}$, sendo que os resultados de alguns modos de vibração estrutural obtidos nesta pesquisa, encontram-se neste intervalo de frequências.

De acordo com o exposto, e a partir dos resultados obtidos na análise modal, percebe-se claramente que os pedestres podem ter sensibilidade quanto às vibrações da passarela avaliada. Os resultados indicam que a partir do quinto modo de vibração, cuja frequência é $0,7552 \mathrm{~Hz}$, os pedestres podem estar suscetíveis a estas vibrações. Destaca-se que esta sensibilidade, varia de indivíduo para indivíduo, sendo a sensibilidade transversal, diferente da sensibilidade longitudinal. Fatores como gênero, idade, tipos de calçado entre outros também são parâmetros que influenciam na percepção das vibrações sentidas. No entanto, os resultados da análise modal também indicaram que as frequências naturais não provocam nenhuma excitação à base (piso) da passarela, ponto na qual os pedestres estão diretamente em contato, mostrando que a estrutura é suficientemente rígida e segura para uso. Uma alteração na rigidez da cobertura da passarela seria uma das alternativas a serem analisadas em estudos futuros, objetivando maximizar o nível de conforto dos pedestres que utilizam a passarela.

\section{REFERÊNCIAS}

ANSYS. v. 16.0 Reference Manual. 2016.

RAO, Singiresu. Vibrações Mecânicas. 4 ed. Ed. Pearson. São Paulo. Brasil. 2009.

REDDY, A. An Introduction to the Finite Element Method, McGraw-Hill Education. $3^{\circ}$ Edição. 2015 
SHIGLEY, Jeseph; MISCHKE, Charles; BUDYNAS, Richard. Projeto de Engenharia Mecânica. $7^{\circ}$ Edição. 2005.

STOYANOFF, Stoyan; HUNTER, Mark. Footbridges: Pedestrian induced vibrations. Rowan Williams Davies and Irwin Inc. Ontario, Canada. 2003.

ŽIVANOVIĆ, Stana; PAVIC, Aleksandar; REYNOLDS, Paul. Vibration serviceability of footbridges under human-induced excitation: a literature review. Journal of Sound and Vibration. Vol. 279, p.1-74. 2005a.

ŽIVANOVIĆ, Stana; PAVIC, Aleksandar; REYNOLDS, Paul. Structure Dynamic Interaction in Footbridges. Journal of Bridge Engineering. Vol. 158 (4), p.165-177. 2005b.

ŽIVANOVIĆ, Stana; DÍAZ, S.; PAVIC, Aleksandar; Influence of Walking and Standing Crowds on Structural Dynamic Properties. In: Proceedings of the 27 Conference and Exposition on Structural Dynamics. Orlando, Flórida USA, 2009. 